\title{
Use of low level laser therapy in the treatment of persistent idiopathic orofacial pain and traumatic trigeminal neuropathy- a pilot study
}

\author{
Vanja Vucicevic Boras' ${ }^{1}$ Ivica Richter ${ }^{2}$, Natasa Zorat ${ }^{3}$, Danica Vidovic Juras' ${ }^{1}$ Vlaho Brailo' and Ana Andabak Rogulj ${ }^{*}$ \\ *Correspondence: anaandabak@gmail.com \\ 'Department of Oral Medicine, School of Dentistry, Gunduliceva 5 and Clinical Hospital Center Zagreb, Croatia. \\ ${ }^{2}$ Dental Unit Fužine, Fužine, Croatia. \\ ${ }^{3}$ Department of Oral Medicine, School of Dentistry, Gunduliceva 5, Croatia.
}

\begin{abstract}
Background: Nerve recovery in the orofacial region is not completely satisfactory. Nowadays, low level laser therapy (LLLT) has been recognized and accepted as a possible therapeutic option in various states of nerve damage throughout the body. LLLT is noninvasive and there are only few contraindications for its use. Therefore, the effect of LLLT on patients with idiopathic orofacial pain and traumatic trigeminal neuropathy was assesed.

Methods: Twenty one patient was enrolled in this pilot study, there were 10 patients with persistent idiopathic facial pain (PIFP) and 11 patients with traumatic trigeminal neuropathy (TTN). Each patient was treated once daily in 10 sessions using a GaAlAs laser $\left(830 \mathrm{~nm}, 3 \mathrm{~W}, 50 \mathrm{~ms}, 50 \mathrm{~Hz}\right.$ which is equivalent to an energy density of $1.5 \mathrm{~J} / \mathrm{cm}^{2}$ ). The outcome ot LLLT was evaluated by means of a patient survey on the relief of symptoms $(0=$ no imporvement, $1=$ partial improvement, $2=$ complete improvement). Statistical analysis was performed by use of descriptive statistics and when needed by use of chi-square test. Values lower than 0.05 were considered as significant.
\end{abstract}

$\underline{\text { Results: }}$ Complete improvement of symptoms was seen in $70 \%$ of the patients with PIFP and in $36.4 \%$ of patients with TTN. LLLT showed no improvement in $10 \%$ with PIFP and $45.4 \%$ of patients with TTN.

Conclusion: It might be concluded that LLLT is beneficial in patients with persistent idiopathic orofacial pain and traumatic trigeminal neuropathy.

Keywords: Low level laser therapy, idiopathic orofacial pain, persistent idiopathic facial pain, traumatic trigeminal neuropathy

\section{Introduction}

Low level laser therapy (LLLT) is becoming more used due to its beneficial effects in various medical conditions but also due to the fact that treatment with LLLT is painfree and has few contraindications [1]. The use of LLLT for peripheral nervous system regeneration is currently being investigated in order to achieve early functional nerve recovery. There are only few studies regarding the use of LLLT for nerve recovery in humans and rats. It seems that LLLT act analgesically since they improve endorphin release and therefore inhibit nociceptive signals and control pain mediators [2]. Low level lasers can also act analgesically by inhibiting pain signals which partially leads to the transient varicosities along the neurons which decrease impulse transmission. Cells are acidic in a lowered redox state, but after laser irradiation they become alkaline and afterwards they can act in an optimal way. It is well known that LLLT stimulate lymphocytes, activate mast cells, and increase production of adenosine triphosphate in the mitochondria and proliferation of various cell types therefore acting as antiinflammatory [2]. Furthermore, LLLT stimulate microcirculation which results in the change of capillary hydrostatic pressure which in turn results in edema absorption and elimination of intermediary metabolites [2]. Rochkind et al., [3] reported that in patients with long-term peripheral nerve injury noninvasive 780-nm laser phototherapy can progressively improve nerve function, which leads to significant functional recovery. GigoBenato et al., [4] reported that $660 \mathrm{~nm}$ LLLT with low $\left(10 \mathrm{~J} / \mathrm{cm}^{2}\right)$ or moderate $\left(60 \mathrm{~J} / \mathrm{cm}^{2}\right)$ energy densities is able to accelerate neuromuscular recovery after nerve crush injury in rats. Peric [5] reported that LLLT (30 treatments during a period of 12 weeks) in patients with diabetic polyneuropathy (control group was given only vitamin therapy) showed decrease in spatial perception threshold and increase in motor medianus conduction. Ohtsuka et al., [6] treated patient with postherpetic neuralgia which manifested as burning pain in the right forehead with LLLT which resulted in the increased blood flow and relieve in neuralgia.

Persistent idiopathic orofacial pain (PIFP) is characterized by poorly localized pain and perceived as arising from muscles of the face and jaw. Symptoms wax and wane in intensity over days and weeks [7]. Traumatic trigeminal neuropathy is usually induced by oral surgical operations, particularly the removal of the impacted lower third molars, being more frequent in females. It can manifest itself with various degrees of sensory loss [8]. Considering the lack of information about the treatment of these conditions and the importance of using conservative therapeutic interventions in the treatment of orofacial pain, the aim of this study was to assess the effect of LLLT in patients 
with painful orofacial conditions.

\section{Methods \\ Subjects}

Twenty one patients, 10 with persistent idiopathic facial pain (PIFP) and 11 with traumatic trigeminal neuropathy (TTN) were involved in this study. Diagnosis of PIFP was carried out according to criteria established the Headache Classification Subcommittee of the International Headache Society [9]: (1) Facial pain present daily for at least 1 month and persisting for all or most of the day. (2) The pain is deep and poorly localized of moderate or severe intensity, but not unbearable. (3) The pain is confined at onset to a limited area on one side of the head. (4) The pain is without paroxysms, precipitation from trigger areas, autonomic symptoms, sensory loss, and other physical signs; but dysaesthesia may occur. Diagnosis of TTN was made upon these criteria: (1) sensory defect (paraesthesia) in the region innervated by maxillary or mandibular nerve following surgical procedure and (2) minimal duration of 3 months. Three experienced dentists who are also academic staff from the Department of Oral medicine, University of Zagreb in Croatia diagnosed the painful conditions.

The exclusion criteria were other orofacial pain conditions due to odontogenic causes, vascular conditions (migraine, etc) and inability of patient to understand the text of the informed consent. None of the patients had systemic diseases nor took meds that might affect their pain.

The study was approved by the Ethical Committee of the University of Zagreb in Croatia and from every patient informed consent according to Helsinki II declaration was obtained.

\section{Laser procedure}

Laser therapy was performed with a galium-aluminumarsenide (GaAlAs) laser (BTL-5000, www.btl.com) with wavelength of $830 \mathrm{~nm}$. Each session was performed on every working day and lasted for 3 min (total number of 10 days). Break was during the weekend.

There were two irradiation cycles during one session, according to the manufacterer's recommendations for the treatment of trigeminal neuralgia. First cycle was $\mathrm{A}$ and consisted of $12 \mathrm{~J} / \mathrm{cm}^{2}$, duty factor $100 \%$, cont.area $1.00 \mathrm{~cm}^{2}$, max power $100 \mathrm{~mW}$, duration 2 minutes and second cycle was $6 \mathrm{~J} / \mathrm{cm}^{2}$, duty factor $80 \%, 10 \mathrm{~Hz}$, area $1 \mathrm{~cm}^{2}$, max power $100 \mathrm{~mW}$, duration $1 \mathrm{~min}$ and $15 \mathrm{sec}$. We did not use placebo as we thaught that patients would suffer even more as they were not given any therapy and were already in much pain. In the case of PIFP laser was applied on the skin at the most painful surface area $\left(1 \mathrm{~cm}^{2}\right)$. In the case of TTN laser application area was on the lingual side ofthe mandible at the extraction site where the surgical injury occurred.

\section{Evaluation and statistical analysis}

Primary endpoint was patients' report on the relief of symptoms $(0=$ no improvement, $1=$ partial improvement,
$2=$ complete improvement).

Statistical analysis was performed by use of descriptive statistics (mean and standard deviation). Differences between the tested groups were assesed by chi-square test. Values lower than 0.05 were considered significant.

\section{Results}

Clinical characteristics of the patients are presented in Table 1. No significant differences in terms of age and gender were found between the two patient groups (PIFP vs. TTN, $p=0.077$; $\mathrm{p}=0.645$ ).

Total resolution of symptoms was achieved in $70 \%$ of patients with PIFP and $36.4 \%$ of patients with TTN. Partial resolution of symptoms was achieved in $20 \%$ of patients with PIFP and $18.2 \%$ of patients with TTN. Treatment showed no improvement in $10 \%$ of patients with PIFP and $45.4 \%$ of patients with TTN. No significant differences in outcome were found between the two groups $(p=0.302)$.

\section{Discussion and conclusion}

Several maxillofacial interventions can induce nerve damage, especially on the inferior alveolar nerve which usually result in the paraesthesias, dysesthesias and painful orofacial conditions. Khullar et al., [10] reported that LLLT has beneficial effect on paraesthesias with lasers 4-6 J per point along the projection of the nerve. The same authors [10] also reported that GaAlAs laser therapy $(820 \mathrm{~nm}, 4 \times 6 \mathrm{~J}$ per treatment, in a total number of 20 treatments) results in both subjective and objective improvement in mechanical sensory perception in long standing neurosensory deficit of the inferior alveolar nerve. Pinheiro et al., [11] used $632.8 \mathrm{~nm}, 670 \mathrm{~nm}$ and 830 $\mathrm{nm}$ diode lasers in patients with temporomandibular joint pain and trigeminal neuralgia. Most of the patients had 12 applications (twice a week) with an average dose of $1.8 \mathrm{~J} /$ $\mathrm{cm}^{2}$. Most treatment consisted of a series of 12 applications (twice a week) and in 15 cases a second series was applied. Patients were treated with an average dose of $1.8 \mathrm{~J} / \mathrm{cm}^{2}$. One hundred fifty four out of 241 patients were asymptomatic at the end of the treatment, 50 improved considerably, and 37 were symptomatic. The results confirmed that LLLT is an effective tool and is beneficial for the treatment of many disorders in the maxillofacial region. Miloro and Repasky [12] demonstrated that neurosensory recovery after bilateral saggital split osteotomy can be significantly improved both in terms of time course and magnitude of return of function with the adjunctive use of LLLT. The authors used LLLT $(4 \times 6 \mathrm{~J}$ per treatment, along the distribution of the inferior alveolar nerve before surgery, 6 and $24 \mathrm{~h}$ after and on the $2 \mathrm{nd}, 3 \mathrm{rd}$, 4th and 7th day).

Ozen et al., [13] treated four female patients after third molar surgery who had paraesthesia with LLLT (GaAlAs laser, the irradiance used was $6 \mathrm{~J}$ per treatment site, applying $5 \mathrm{~mW}$ in continuous mode wave for $90 \mathrm{~s}$ in total of 20 treatments performed every second day) and concluded that LLLT 
Table 1. Clinical characteristics of the patients.

\begin{tabular}{|c|c|c|c|c|c|c|}
\hline No. & Gender & $\begin{array}{c}\text { Age } \\
\text { (years) }\end{array}$ & Diagnosis & Site & $\begin{array}{l}\text { Duration of } \\
\text { symptoms } \\
\text { (months) }\end{array}$ & Outcome \\
\hline $\mathrm{P} 1$ & male & 71 & PIFP & Maxillary ridge, frontal region & 3 & Partial improvement \\
\hline $\mathrm{P} 2$ & male & 60 & PIFP & Mandibular ridge, left molar region & 14 & No improvement \\
\hline P3 & female & 72 & PIFP & Left mental region & 27 & Complete resolution \\
\hline $\mathrm{P} 4$ & female & 62 & PIFP & Left mental region & 36 & Complete resolution \\
\hline P5 & female & 69 & PIFP & Right tongue border & 3 & Partial improvement \\
\hline P6 & female & 59 & PIFP & Maxillary ridge, right molar region & 60 & Complete resolution \\
\hline P7 & female & 69 & PIFP & Mandibular ridge, left molar region & 6 & Complete resolution \\
\hline P8 & female & 52 & PIFP & Maxillary ridge, right molar region & 72 & Complete resolution \\
\hline P9 & female & 64 & PIFP & Maxillary ridge, right premolar region & 15 & Complete resolution \\
\hline P10 & female & 53 & PIFP & Maxillary ridge, left premolar region & 5 & Complete resolution \\
\hline P11 & male & 47 & TTN & Left tongue border & 3 & Complete resolution \\
\hline P12 & female & 33 & TTN & Left buccal mucosa & 6 & Complete resolution \\
\hline P13 & female & 52 & TTN & Left tongue border & 5 & No improvement \\
\hline P14 & female & 62 & TTN & Lower lip, right side & 9 & Complete resolution \\
\hline P15 & male & 75 & TTN & Left mental region & 5 & No improvement \\
\hline P16 & female & 57 & TTN & Right tongue border & 84 & Partial improvement \\
\hline P17 & male & 66 & TTN & Lower lip, left side & 120 & No improvement \\
\hline P18 & female & 66 & TTN & Right tongue border, lower lip right side ${ }^{\star}$ & 3 & No improvement \\
\hline P19 & female & 52 & TTN & Left buccal mucosa & 12 & Partial improvement \\
\hline P20 & female & 52 & TTN & Lower lip, left side & 18 & No improvement \\
\hline P21 & male & 45 & TTN & Lower lip, left side & 4 & Complete resolution \\
\hline
\end{tabular}

PIFP- persistent idiopathic facial pain, TTN- traumatic trigeminal neuropathy

${ }^{*}$ When two sites were affected each site underwent 10 sessions as described in 'Subjects and methods' chapter.

reduces long-standing sensory nerve impairment following third molar surgery.

Saber et al., [14] concluded that there was a significant difference in pain level between laser and placebo group after third molar surgery, however there was no difference in pain duration between the two tested groups. On the other hand, Lopez-Ramirez et al., [15] reported that LLLT $(810 \mathrm{~nm}$, output power $0.5 \mathrm{~W}$ and $5 \mathrm{~J} / \mathrm{cm}^{2}$ energy density) did not show beneficial effects in reducing pain, swelling and trismus after extraction of the impacted molars.

Eckerdal and Bastian [16] treated patients with laser (830 $\mathrm{nm}, 30 \mathrm{~mW}$ ) for five weeks. The results demonstrated that out of 16 patients, ten were painfree, two had decreased pain levels while in four there was no change.

Moore et al., [17] also evaluated the use of Ga-Al-As diode laser $(830 \mathrm{~nm}, 60 \mathrm{~mW})$ in patients with postherpetic neuralgia and demonstrated significant reduction in the pain intensity in their patients.

More recent studies such as one of Yang and Huang [18] studied LLLT in 16 patients with persistent idiopathic orofacial pain (PIFP) and average pain reduction of $43.47 \%$ (ranging from 9.3\% to 91.8\%) was achieved which is lower percentage in comparison to our sample (70\%). However, hteir patients received LLLT between one to ten times, whereas all our patients received the same LLLT regimen (ten times altogether). The same authors concluded [18] that LLLT may be an effective treatment for PIFP.

On the other hand, Tengrungsun et al., [19] concluded on the literature systematic review that there is only limited evidence suggesting that LLLT is more effective than placebo, sham laser and other active treatment in the treatment of orofacial pain.

Last but not least we have to mention the limitations of present study: small number of patients, self evaluation of symptoms (visual analogue scale should be used in the future), lack of placebo group (we didnt use placebo i.e., laser switched off as patients were in pain and already suffered a lot) and different duration of symptoms (the duration of the symptoms should be divided into acute and chronic in the future studies). However, certain strenghts such as beneficial outcome after LLLT, experienced researchers who conducted the study and homogenous group of patients in terms of 
not taking meds and not having systemic diseases are also seen in this paper.

The results of our study show that LLLT could have beneficial effect on patients with orofacial pain as total resolution of symptoms was achieved in $70 \%$ of patients with PIFP and $36.4 \%$ of patients with TTN.

\section{Competing interests}

The authors declare that they have no competing interests.

\section{Authors' contributions}

\begin{tabular}{|l|c|c|c|c|c|c|}
\hline Authors' contributions & VVB & IR & NZ & DVJ & VB & AAR \\
\hline Research concept and design & $\sqrt{ }$ & -- & - & - & -- & -- \\
\hline Collection and/or assembly of data & -- & -- & $\sqrt{ }$ & -- & -- & -- \\
\hline Data analysis and interpretation & -- & $\sqrt{ }$ & -- & - & -- & -- \\
\hline Writing the article & -- & -- & -- & -- & -- & $\sqrt{ }$ \\
\hline Critical revision of the article & -- & -- & -- & $\sqrt{ }$ & -- & -- \\
\hline Final approval of article & $\sqrt{ }$ & -- & -- & -- & -- & -- \\
\hline Statistical analysis & -- & -- & -- & -- & $\sqrt{ }$ & -- \\
\hline
\end{tabular}

\section{Acknowledgement}

The authors wish to thank Mirjana Majic, Branka Crnkovic and Matea Ljubicic for help during laser sessions. The authors also wish to thank to the Croatian Ministry of Science and Technology for their support (project number: 065-0650445-0485).

\section{Publication history}

EIC: W. Scott Argraves, Medical University of South Carolina, USA. Received: 25-Mar-2013 Revised: 06-Jun-2013

Re-Revised: 06-Aug-2013 Accepted: 06-Sep-2013

Published: $17-$ Sep-2013

\section{Reference}

1. Tuner J, Beck Kristensen PH. Low-Level Lasers in Dentistry, ed. Convissar RA. In Principles and practice of laser dentistry, St.Louis Mosby Elsevier 2011. | Book

2. Tezel A, Kara C, Balkaya V and Orbak R. An evaluation of different treatments for recurrent aphthous stomatitis and patient perceptions: Nd:YAG laser versus medication. Photomed Laser Surg. 2009; 27:101-6. | Article | PubMed

3. Rochkind S, Drory V, Alon M, Nissan M and Ouaknine GE. Laser phototherapy $(780 \mathrm{~nm})$, a new modality in treatment of long-term incomplete peripheral nerve injury: a randomized double-blind placebo-controlled study. Photomed Laser Surg. 2007; 25:436-42. | Article | PubMed

4. Gigo-Benato D, Russo TL, Tanaka EH, Assis L, Salvini TF and Parizotto NA. Effects of 660 and $780 \mathrm{~nm}$ low-level laser therapy on neuromuscular recovery after crush injury in rat sciatic nerve. Lasers Surg Med. 2010; 42:673-82. | Article | PubMed

5. Peric Z. [Influence of low-intensity laser therapy on spatial perception threshold and electroneurographic finding in patients with diabetic polyneuropathy]. Srp Arh Celok Lek. 2007; 135:257-63. | Article | PubMed

6. Ohtsuka H, Kemmotsu O, Dozaki S and Imai M. [Low reactive-level laser therapy near the stellate ganglion for postherpetic facial neuralgia]. Masui. 1992; 41:1809-13. | PubMed

7. List T, Feinmann C. Persistent idiopathic facial pain. Ed; Zakrzewska JM. Orofacial pain. Oxford University press. New York, 2009. | Book

8. Penarrocha MA, Penarrocha D, Bagan JV and Penarrocha M. Posttraumatic trigeminal neuropathy. A study of 63 cases. Med Oral Patol Oral Cir Bucal. 2012; 17:e297-300. | Pdf | PubMed Abstract | PubMed FullText

9. The International Classification of Headache Disorders: 2nd edition. Cephalalgia. 2004; 24 Suppl 1:9-160. | Article | PubMed
10. Khullar SM, Emami B, Westermark A and Haanaes HR. Effect of low-level laser treatment on neurosensory deficits subsequent to sagittal split ramus osteotomy. Oral Surg Oral Med Oral Pathol Oral Radiol Endod. 1996; 82:132-8. | Article | PubMed

11. Pinheiro AL, Cavalcanti ET, Pinheiro TI, Alves MJ, Miranda ER, De Quevedo AS, Manzi CT, Vieira AL and Rolim AB. Low-level laser therapy is an important tool to treat disorders of the maxillofacial region. J Clin Laser Med Surg. 1998; 16:223-6. I PubMed

12. Miloro $M$ and Repasky M. Low-level laser effect on neurosensory recovery after sagittal ramus osteotomy. Oral Surg Oral Med Oral Pathol Oral Radiol Endod. 2000; 89:12-8. | Article | PubMed

13. Ozen T, Orhan K, Gorur I and Ozturk A. Efficacy of low level laser therapy on neurosensory recovery after injury to the inferior alveolar nerve. Head Face Med. 2006; 2:3. | Article | PubMed Abstract | PubMed FullText

14. Saber K, Chiniforush $N$ and Shahabi S. The effect of low level laser therapy on pain reduction after third molar surgery. Minerva Stomatol. 2012; 61:319-22. | PubMed

15. Lopez-Ramirez M, Vilchez-Perez MA, Gargallo-Albiol J, ArnabatDominguez $J$ and Gay-Escoda C. Efficacy of low-level laser therapy in the management of pain, facial swelling, and postoperative trismus after a lower third molar extraction. A preliminary study. Lasers Med Sci. 2012; 27:559-66. | Article | PubMed

16. Eckerdal A and Bastin L. Can low reactive-level laser therapy be used in treatment of neurogenic facial pain?A double blind placebo controlled investigation of patients with trigeminal neuralgia. Laser Therapy. 1996; 2: 247-51. | Article

17. Moore KC, Hira N, Kumar PS, Jayakumar CS and Ohshiro T. A double blind crossover trial of low level laser therapy in the treatment of post herpetic neuralgia. Laser Ther. 1988; 1:7-9. | Pdf

18. Yang HW and Huang YF. Treatment of persistent idiopathic facial pain (PIFP) with a low-level energy diode laser. Photomed Laser Surg. 2011; 29:707-10. | Article | PubMed

19. Tengrungsun $T$, Mitriattanakul S, Buranaprasertsuk $P$ and Suddhasthir T. Is low level laser effective for the treatment of orofacial pain?: A systematic review. Cranio. 2012; 30:280-5. | Article | PubMed

\section{Citation:}

Vucicevic Boras V, Richter I, Zorat N, Vidovic Juras D, Brailo V and Andabak Rogulj A. Use of low level laser therapy in the treatment of persistent idiopathic orofacial pain and traumatic trigeminal neuropathy- a pilot study. J Regen Med Tissue Eng. 2013; 2:5. http://dx.doi.org/10.7243/2050-1218-2-5 